\title{
The Future of Criminological Theory: Tendency and Construction Methods
}

\author{
Xiaofei Wang, Ying Zhuang \\ Research Institute of Criminal Justice of Virtual Reality Space, Nanchang Vocational College, Nanchang, China \\ Email:wxfcriminology@yeah.net
}

How to cite this paper: Wang, X.F. and Zhuang, Y. (2018) The Future of Criminological Theory: Tendency and Construction Methods. Open Access Library Journal, 5 e4492.

https://doi.org/10.4236/oalib.1104492

Received: March 10, 2018

Accepted: March 27, 2018

Published: March 30, 2018

Copyright (C) 2018 by authors and Open Access Library Inc.

This work is licensed under the Creative Commons Attribution International License (CC BY 4.0).

http://creativecommons.org/licenses/by/4.0/

\section{(c) () Open Access}

\begin{abstract}
At present, most famous criminologists believe that the future trend of criminology theory is to construct the general theory of crime by theoretical verification and theoretical integration. On the basis of criticizing the two construction methods separately, this study finds that in the future, only the crime theory that general theory of crime of unlimited approaching can be constructed. And it puts forward the construction methods: one is the good and evil of human nature is integrated. The second is the integrated explanation of law-abiding behavior and crime behavior. The third is the integrated explanation of conducive to criminals and crime behavior.
\end{abstract}

\section{Subject Areas}

Criminology, Sociology

\section{Keywords}

General Theory of Crime, Human Nature, Law-Abiding Behavior, Crime Behavior

\section{Introduction}

The future of criminological theory tends toward a general theory of crime [1] [2] [3]. There are two main methods to construct general theory of crime: 1) theoretical verification, 2) theoretical integration, with the purpose of enhancing the theoretical explanation of criminology. However, this study argues that criminology theory is to explain crime phenomenon and reveal crime rule, in the future it is impossible to develop a general theory that can explain all crimes, only the crime theory that general theory of crime of unlimited approaching can be constructed, that is, the explanatory power is infinitely close to the explana- 
tory power of general theory. The fundamental reason is that there are factual and theoretical tensions between crime phenomena and criminological theories. This study not only indicates the development trend and construction methods of future criminology theory, but also provides a new perspective for development of crime control policies. The study consists of three parts: one is the criticism of theoretical verification; the second is the criticism of theoretical integration; the third is the construction methods.

\section{Criticism of Theoretical Verification}

In terms of theoretical verification, most western criminologists are currently working on two tasks: 1) cross-cultural verification. Use different regions or countries qualitative or quantitative criminal data verification criminology theory [4] [5] [6], 2) cross-type verification. Use different types of crime phenomenon to verify criminological theory [7] [8]. These efforts stem from criminology as a worldwide discipline that seeks to construct general theory of crime. Under such circumstances, Chinese criminology faces the dual tendency of internationalization and localization, which requires us to actively seek mechanisms and methods for resolving conflicts, the development of local criminological theory cannot break the connection between the criminological theory in our country and the criminological theory in other countries or regions. On the contrary, it is necessary to bring the criminological theory in our country into the world criminological system.

Since criminology is a worldwide discipline, criminology theory should be able to explain different types of crime or criminal behavior in the same country or region, and should be able to explain different types of crime or criminal behavior in different countries or regions. However, the criminology theory in foreign countries with various types and different theoretical tendencies has only partial explanatory power [9], mainly in two aspects: First, cannot fully explain a certain type of crime phenomenon or criminal behavior, second, can explain such crime phenomenon or criminal behavior, but cannot or cannot fully explain other types of crime phenomenon or criminal behavior. The Explanatory power of Criminology theory is Influenced by Three Factors: Crime Phenomenon, Crime Cause and Causation [10], It includes two aspects: First, any type of crime phenomenon or criminal behavior is the Comprehensive effect result of different types of factors, and the causal relationship is mechanistic and situational, which makes the criminology theory difficult to fully explain a certain type of crime phenomenon or crime behavior. The causal factors and their processes that affect such crimes are complex. The nature of the causal factors can be divided into social factors, economic factors, natural environmental factors, biological factors, psychological factors, and each category also includes a number of specific factors. The interaction between various types of causal factors is quite complicated, mainly because it is difficult to solve three problems: 1) How do they interact with each other? 2) What causes factors when work? 3) How to accurately determine the force of each causal factor. In addition, causal 
relationship with the mechanism and situational. "In the recent 20 years, the new trend of western criminal science research is to scientifically carry out the crime prevention and control policy by empirical research methods, specifically, the data collection, analysis and crime prevention policies are completely unified." [11] In the process of data quantitative analysis, other variables will be controlled in order to obtain pure causation, but adding control variables may lead to non-true causality because causation is both mechanistic and contextual [12].

Second, there are two kinds of logic errors in the construction of criminological theory. Originate from not paying enough attention to the differences between different kinds of Crime phenomenon or criminal behavior, which makes criminology theory difficult to explain completely different types of Crime phenomenon or criminal behavior. on the one hand, Mistaken part of the common point of all crime phenomena as common point of all the crime phenomenon and the whole content of the its relationship, As some scholars have said: "Type studies limit objects to specific parts and cannot build macroscopic theories of crime." [13] On the other hand, the mistaken belief that there is something in common between different crimes means that a general explanation of all crimes can be made. The use of typology in criminological studies is based on the classification of crime phenomena, in order to examine the similarities or differences between the various types of crime phenomena by comparison, thereby establish criminology theory. The same point exists not only in the conceptual level of abstraction, but also in the specific factors of crime, as a method of study crime phenomenon, it is not suitable for constructing the crime theory, which may lead to an unreasonable analogical reasoning. Although there are commonalities between different types of crime phenomena or criminal behavior, it does not mean that general theories of crime can be constructed: 1) "Crime phenomena" or "criminal behavior" and "crime causes" are two different concepts. "Crime phenomenon or criminal behavior" is caused by the crime. 2) There are many types of causal relationships between different types of crimes and their causes.

3) The causes of various types of crime exist at different times [14].

\section{Criticism of Theoretical Integration}

"Strictly speaking, the traditional criminology is the study the causes of crime" [15]. The integration of criminological theory is essentially the integration of the crime causes. To carry out the integration of criminological theory need to answer two questions: First, why integration? Integration of criminological theory objectively can enhance explanatory power of criminological theory, formally, can reduce the number of criminological theory; Second, how to integrate? Methods include: theory (Integration between theories), analysis hierarchy, interdisciplinary, methods. Academic integration is mainly the first type [16], Specific includes three ways: First, integrate crime causes into a concept; second, integrate different crime factors to jointly explain crime; the third is to establish a causal relationship between crime factors to explain crime [17]. 
However, these three methods still have some limitations in constructing the general theory of crime: 1) The conceptual integration of Crime factor can only be a type of limited integration. "Many scholars believe that crime is the product of many different factors; it is impossible to theoretically integrate these factors now or ever." [18] It is unrealistic to carry out a single conceptual integration of all crime factors. The difficulties include two aspects: Firstly, it is difficult to find a concept that can integrate enough crime factors; Second, even if there is a concept that can integrate enough crime factors, the guiding role of crime prevention policies is limited, because such a concept must be quite macroscopic and macroscopic concepts lead to unmanageable crime prevention policies. Therefore, only type of integration of crime factors, the main consideration of how the same nature crime factors of different criminology theory, integrated into a superior concept. 2) From the theoretical structure, some criminology theories do not integrate each other. As the book "Theoretical CriminologyFrom Modern to Postmodern", it is considered that there are at least 11 theoretical structures in modern criminology that are incompatible with each other because of different interpretations of human nature, deviance reasons and social order etc. [19]. 3) From the aspect of prevention policy, the integration of certain crime factors will affect the effectiveness of the policy. Reasons include two aspects: First, part of the crime causes is impossible or difficult to eliminate. Such as human nature of egoism; second is to eliminate some of the crime factors does not comply with rationality principle.

\section{Methods of Build Theory of Infinite Approach to General Theory of Crime}

Methods include three aspects: 1) Integrate the most basic assumptions about human nature in different cultures where different types of crimes are located. 2) Regard all kinds of crimes as a whole and out of crime, not to study the commonalities or differences between different kinds of crimes. 3) Return to people's "rational." The differences between Chinese and Western crime and crime causes from the differences between Chinese and Western cultures. However, a large number of historical facts also show that the differences between Chinese and Western cultures are not the root causes of conflicts but complementary premise [20].

\subsection{Integration of Good and Evil of Human Nature}

In order to explain the crimes that take place in countries or regions of different cultural backgrounds, the most basic assumption of humanity in Chinese and Western cultures must be integrated. Traditional criminology is the usual way to study the causes of crime: "Why do some people commit crimes? Or" Why do some people not? The core of question is the "person" who commits or does not commit crimes, the nature that fundamentally decides and interprets human behavior is human nature. Although we can think that two questions is answer 
the same question, Because some people commit crimes must mean that some people do not commit crimes, but the two assumptions about human nature are different, ignoring this point will mistakenly believe that the two questions are the same, If we regard people who commit crimes and others who do not commit crimes as a whole, It can also show that human nature is both "good" and "evil". Why do some people commit crimes? The assumption of human nature is "human nature evil". Why do some people not? The hypothesis of human nature is "human nature good". The former is the most basic assumption of "Western culture for" "human nature". Western culture of "human nature evil" emphasizes humanistic egoism as the root of crime in explaining the crime causes. The latter is the most basic assumption of "human nature" in Chinese culture. The view of human nature in traditional Chinese culture is also diverse, including good nature, evil, and not good and evil. However, people have inherited Confucian views on the theory of "nature of good people" and Emphasize the social factors and the adverse environmental effects on human nature and crime.

From a personal point of view, individuals also have both Good humanity and Human evil. The factual premise established by the theory model of progressive social informal control theory is the coexistence of the stability and variability of crime behavior in the process of life. To solve two problems: "Why does a person sometimes commit crimes?" and "Why does a person sometimes sin?" That is to say, crime or non-crime is the result of individual choice. This also shows that it is unscientific to designate human nature as single and absolute as "good" or "evil" and that human nature is both "good" and "evil". Therefore, based on obtaining a certain material or spiritual benefit, a person will choose the behavior, including crime behavior and legal behavior, but this selection process is affected by other factors such as social factors.

The integrated design of good human nature and evil human nature: "Why do people give up expecting material or spiritual gains by legal actions?" Here are two meanings: First, to give up legal actions to obtain expected material or spiritual gains by crime behavior. Humanity is assumed to be "human evil"; second, if the expected material or spiritual gain can be obtained by legal behavior, then legal behavior is implemented. The human nature behind is assumed to be "human good". This type of interrogation differs from "Why get the expected benefits through crime behavior?" The difference is mainly in two aspects: 1) The hypothesis of human nature of the latter type of questioning is only "human evil." 2) The latter logically does not necessarily need to answer "the reason why legitimate behavior cannot achieve expected returns." From the perspective of "Why does the perpetrator fail to obtain the expected material or spiritual benefit through legal action?" from the perspective of explaining the reasons for the crime, two questions need to be answered: First, the reasons why legitimate behavior cannot obtain expected benefits. Second, the crime behavior can obtain the expected benefits. The scope of interpretation of this type of interrogation of human nature has also been expanded. It is expressed as follows: 1) It can ex- 
plain the crimes committed by the perpetrators in different cultural backgrounds in China and in the West. 2) It can explain that some people in a group commit crimes or some people do not commit crimes. 3) It can be explained that individuals sometimes commit crimes and sometimes do not commit crimes.

\subsection{Integrated Interpretation of Law-Abiding Behavior and Crime Behavior}

The criminology theory cannot take into account all commonalities and differences between different types of crimes, this has led to its limited explanatory power. The reason is that the crime phenomenon is regarded as the theoretical premise of criminology, the theoretical study of criminology still does not jump out of the research perspective of examining the crime phenomenon from inside. The solution is to treat the crime phenomena and law-abiding as the theoretical premise of criminology. The traditional theory of criminology pays attention to the crime itself and its causes. To a certain extent, it ignores the relationship between legal behavior and crime behavior is unreasonable: 1) The purpose of researching crime causes and formulating crime prevention policies is to make people obey law or not violate law. 2) The crime reason defined by the current criminological theory actually affects not only crime behavior but also legal behavior. It merely promotes crime behavior and acts as a deterrent to legitimate behavior. Therefore, in fact, the current criminology theory has not been able to fully investigate the crime causes from the purpose of reason study and the role of crime-causing factors.

How to study crime causes from the perspective of Law-abiding behavior and crime behavior? Previous criminology theories have studied the crime causes from the perspective of Law-abiding behavior and crime behavior, mainly include Learning theory and stress theory. The former explains the crime cause from the perspective of analogy between crime behavior and Law-abiding behavior and believes that crime behavior and Law-abiding behavior are obtained through learning. The latter regards lack of institutional means (legal means) as a crime cause.

Why give up Law-abiding behavior? Stress theory points out that potential criminal face five choices of economic goals and institutional measures, including giving up institutional measures. However, it did not answer the reason for giving up institutional means. The core elements to be considered in the study of the crime causes include the purpose of the potential offender, Law-abiding behavior, crime behavior, and conditional factors that also affect legitimate behavior and crime behavior. There is a certain condition for the mutual transformation between Law-abiding behavior and crime behavior. This condition is that one of Law-abiding behavior and crime behavior cannot achieve the goal of potential offender, and the other can achieve its purpose.

\subsection{Integrated Interpretation of Benefits People and Behavior}

In the construction of the general theory of crime, two points that crime beha- 
vior conducive to human beings and existence of conditions conducive to crime behavior have been involved in previous studies. The most basic considerations of potential offenders in committing crimes include: 1) Crime behavior conducive to human beings. Since the purpose of the crime directly controls the direction and form of the specific crime, if the crime cannot achieve its purpose, the potential offender may give up or continue to commit the crime. However, there are two things to note: first, only when a crime behavior cannot achieve the crime goal for a long time, criminals may completely abandon such crimes. Second, the high concealment of crime behavior itself will weaken the preventive effect, which may lead the perpetrator to continue to achieve its purpose so long as to engage in such crime behavior. 2) Existence of conditions conducive to crime behavior. The reasons for studying conditional factors of crime include two aspects: First, there is a lack of more comprehensive and systematic theory of crime condition factors. The factors that affect crimes can be divided into: causal factors, deterrence factors, and conditional factors. The mainstream criminology theory is basically about the crime cause. Although some foreign criminologists use the word "conditions," they are essentially referring to the crime causes. Second, factors that have a causal relationship with crime are affected by conditional factors of crime.

\section{Conclusion}

This article studies the development trend and construction methods of future criminology theory. The three methods can enhance explanatory power of criminological theory on cross-cultural crime phenomenon. However, the methods proposed in this study are based only on Chinese and Western cultures, and with Social development, culture is also developing, so in the future it is necessary to develop many methods with more cultural background.

\section{References}

[1] Agnew, R. (2013) Integrating Assumptions about Crime, People, and Society: Response to the Reviews of toward a Unified Criminology. Journal of Theoretical \& Philosophical Criminology, 5, 74.

[2] Wang, P. and Lin, L.M. (2014) Crime, Shame and Reintegration. Chinese People's Public Security University Press, Beijing, 1-2.

[3] Gottfredson, M.R. and Hirschi, T. (1990) A General Theory of Crime. Stanford University Press, Redwood City, CA.

[4] Agnew, R. (2015) Using General Strain Theory to Explain Crime in Asian Societies. Asian Journal of Criminology, 10, 131-147. https://doi.org/10.1007/s11417-014-9198-2

[5] Cheung, N.W. and Cheung, Y.W. (2008) Self-Control, Social Factors, and Delinquency: A Test of the General Theory of Crime among Adolescents in Hong Kong. Journal of Youth and Adolescence, 37, 412-430. https://doi.org/10.1007/s10964-007-9218-y

[6] Yun, M. and Kim, E. (2015) Illicit Drug Use among South Korean Offenders: Assessing the Generality of Social Learning Theory. International Journal of Offender 
Therapy and Comparative Criminology, 59, 1166-1187.

https://doi.org/10.1177/0306624X14530671

[7] Agnew, R., Piquero, N.L. and Cullen, F.T. (2009) General Strain Theory and WhiteCollar Crime. In: The Criminology of White-Collar Crime, Springer, New York, 35-60. https://doi.org/10.1007/978-0-387-09502-8_3

[8] Moon, B., Hwang, H.W. and McCuskey, J.D. (2011) Causes of School Bullying: Empirical Test of a General Theory of Crime, Differential Association Theory, and General Strain Theory. Crime \& Delinquency, 57, 849-877. https://doi.org/10.1177/0011128708315740

[9] Wang, Y.F. (2009) On Criminology Theory and Its Construction. Criminal Law Review, No. 2, 237-266.

[10] Wang, Y. (2015) Study on the Crime Cause and Explanatory power of Criminology theory. Juvenile Delinquency Prevention Research, No. 4, 3-9.

[11] Shi, M.Z. (2013) Some Frontier Issues in the Empirical Study of Criminology-A Review of Criminology Master in International Crime Control Science. Issues on Juvenile Crimes and Delinquency, No. 1, 118-119.

[12] Wu, S.R. (2015) The Counterfactual, Control Variables and Text: A Discussion with Professor Liu Linping. Journal of Yunnan University (Social Sciences Edition), 14, 69-75.

[13] Zhang, X.H. (2000) Characteristics of Criminology Theory. Issues on Juvenile Crimes and Delinquency, No. 5, 4-7.

[14] Agnew, R. (2011) Crime and Time: The Temporal Patterning of Causal Variables. Theoretical Criminology, 15, 115-139. https://doi.org/10.1177/1362480609356671

[15] Wang, M. (2009) From "Cause Criminology" to "Existential Criminology"-Redefining the Concept of Criminology. Journal of Social Science of Jilin University, 49, 33-38.

[16] Wickström, P.O.H. and Sampson, R.J. (Eds.) (2006) The Explanation of Crime: Context, Mechanisms and Development. Cambridge University Press, Cambridge, 1. https://doi.org/10.1017/CBO9780511489341

[17] Cao, L.Q. and Zhou, S.X. (2007) Criminology Theory and Empirical. Mass Press, Beijing, 251-252.

[18] Edwin, Sutherland, Donald and Cressey (2009) Criminology. 11th Edition, WU Zhongxian et al. Translation, Chinese People's Public Security University Press, Beijing, 92.

[19] Wayne, M. and Liu, R.W. (2005) Construction of Criminology Theory in Postmodernism. Jinling Law Review, No. 2, 92-106.

[20] He, X.L. (2011) Differences and Complements between Chinese and Western Cultures. Thought Front, 37, 98-105. 